\title{
Defluoridation of Groundwater Using Raw Bauxite: Rural Domestic Defluoridation Technology
}

\author{
Samson Sajidu ${ }^{1}$, Chikumbusho Kayira ${ }^{1}$, Wellington Masamba ${ }^{2} \&$ Jonas Mwatseteza $^{1}$ \\ ${ }^{1}$ Department of Chemistry, Chancellor College, Zomba, Malawi \\ ${ }^{2}$ Harry Oppenheimer Okavango Research Centre, University of Botswana, Maun, Botswana \\ Correspondence: Chikumbusho Kayira, Department of Chemistry, Chancellor College, Zomba, Malawi. E-mail: \\ kayirachiku@yahoo.com
}

Received: April 5, 2012 Accepted: May 30, 2012 Online Published: July 10, 2012

doi:10.5539/enrr.v2n3p1

URL: http://dx.doi.org/10.5539/enrr.v2n3p1

\begin{abstract}
The objective of this study was to develop a rural domestic defluoridation technology for the removal of fluoride from groundwater using locally available raw bauxite. Drinking groundwater sample of high fluoride concentration $(6.17 \mathrm{mg} / \mathrm{L})$ was collected from a borehole in Machinga district of Southern Malawi where dental fluorosis is prevalent due to the high fluoride. Defluoridation of the water sample was done in a model domestic defluoridation unit in batch mode to optimize raw bauxite dosage and contact time. Sand and charcoal were used for water clarification. Optimum bauxite dosage and optimum contact time were determined as $0.150 \mathrm{~kg} / \mathrm{L}$ and 15.0 min respectively. An optimum combined dosage of sand and charcoal for water clarification was found to be $0.720 \mathrm{~kg} / \mathrm{L}$. The specific safe water yield for this system was found to be $36.0 \mathrm{~L} / \mathrm{kg}$ adsorbent. An empirical model of the form $Y=m x+C$ where $\mathrm{Y}$ is the specific safe water yield, $\mathrm{x}$ is the height/cross sectional area ratio of a defluoridator is developed to show the significance of defluoridator design in defluoridation.
\end{abstract}

Keywords: defluoridation, groundwater, raw bauxite, charcoal, rural, technology

\section{Introduction}

In Malawi high levels of fluoride in groundwater used for drinking in some rural areas is well documented (Sajidu et al., 2008; Carter \& Bennet, 1973). Excess fluoride is detrimental to human health. In fact the World Health Organization (WHO) recommends a safe intake of between 0.5 to $1.5 \mathrm{mg} / \mathrm{L}$ from drinking water depending on local temperature (WHO, 2004) whereas the Malawi Bureau of Standards (MBS) has a provisional guideline value of $2.0 \mathrm{mg} / \mathrm{L}$ (MBS, 2005). Above the recommended guideline values in drinking water, fluoride is associated with dental fluorosis where there is defective matrix formation in teeth due to excessive deposition of fluoroapatite instead of hydroxyapatite (WHO, 1994) characterized by blackened, mottled, discolored and chalky white teeth. Other forms of fluorosis are: Skeletal fluorosis, crippling fluorosis and non-skeletal fluorosis

Water defluoridation offers a viable remedy to the problem of high fluorides in drinking water and fluorosis where other options are not available. Various methods of water defluoridation based on precipitation, adsorption, ion exchange, electrodialysis, biosorption, electrochemical methods and membrane filtration have been investigated (Zeni et al., 2005). Some of these methods however, are either inefficient or require advanced technological and large financial investments; hence they are not feasible in developing countries. Thus, there is a growing interest in using low-cost methods and local materials that are efficient to remove excess fluoride from drinking water before it may cause health problems.

Recent studies in Malawi have shown that raw bauxite from Mulanje Mountain has high potential for the defluoridation of water of up to $94.8 \%$ (Sajidu et al., 2008). This previous work however involved jar tests using simulated fluoride contaminated water (deionised water to which fluoride salts had been added). Because of the experimentation procedure and that the water has physical and chemical characteristics different from those of groundwater, field conditions at village level were not simulated, hence the findings do not directly impart on the problem of high fluorides and fluorosis. The objective of this study was therefore to adapt rural domestic drinking water storage containers (clay pots) for fluoride removal from groundwater using raw bauxite obtained from Mulanje Mountain in Malawi. 


\section{Materials and Methods}

\subsection{Materials}

Raw bauxite used in this study was obtained from Lichenya plateau on Mulanje Mountain in Mulanje district through the Geological Survey Department in Zomba, Malawi. The raw bauxite was crushed and sundried to constant mass and sieved into particle sizes of less than $0.5 \mathrm{~mm}$. The material was then stored in air tight polythene paper bags.

Fluoride contaminated groundwater samples were obtained from a borehole in a fluorosis endemic area in Machinga district, Southern Malawi. The characteristics of the groundwater are reported in Table 1.

Table 1. Raw water quality parameters

\begin{tabular}{ll}
\hline Parameter & \\
\hline Fluoride $(\mathrm{mg} / \mathrm{L})$ & $6.17 \pm 0.14$ \\
$\mathrm{pH}$ & $1027 \pm 6.03$ \\
$\mathrm{EC}(\mu \mathrm{S} / \mathrm{cm})$ & $15.6 \pm 1.15$ \\
Chloride $(\mathrm{mg} / \mathrm{L})$ & $18.9 \quad \pm 1.22$ \\
Sulphate $(\mathrm{mg} / \mathrm{L})$ & $\mathrm{bdl}$ \\
Nitrate $(\mathrm{mg} / \mathrm{L})$ & $\mathrm{bdl}$ \\
Phosphate $(\mathrm{mg} / \mathrm{L})$ & $115 \pm 4$ \\
Total hardness $(\mathrm{mg}$ CaCO3/L) & $0.73 \pm 0.01$ \\
Turbidity $(\mathrm{NTU})$ & $25 \pm 0.01$ \\
Total suspended solids $(\mathrm{mg} / \mathrm{L})$ & $8.39 \pm 0.25$ \\
Calcium $(\mathrm{mg} / \mathrm{L})$ & $7.56 \pm 0.09$ \\
Magnesium $(\mathrm{mg} / \mathrm{L})$ & $1.54 \pm 0.10$ \\
Sodium $(\mathrm{mg} / \mathrm{L})$ & $5.95 \pm 0.18$ \\
Potassium $(\mathrm{mg} / \mathrm{L})$ & bdl \\
Iron $(\mathrm{mg} / \mathrm{L})$ & bdl \\
Aluminium $(\mathrm{mg} / \mathrm{L})$ &
\end{tabular}

bdl means below detection limit: $\mathrm{NO}_{3}^{-}(0.002 \mathrm{mg} / \mathrm{L}) ; \mathrm{PO}_{4}(0.003 \mathrm{mg} / \mathrm{L})^{-} ; \mathrm{Fe}(0.005 \mathrm{mg} / \mathrm{L})$; and $\mathrm{Al}(0.01 \mathrm{mg} / \mathrm{L})$

Defluoridation of water using bauxite colorizes the water (Sajidu et al., 2008); therefore sand and charcoal were used in the study for water clarification. Plant charcoal and river sand were purchased locally in Zomba. The sand was thoroughly washed with tap water followed by distilled water then sundried to constant mass.

Analytical grade chemicals used in this study were purchased from Lab Enterprises (Ltd) in Malawi. Distilled water was used in preparation of all standard solutions and other analyses.

\subsection{Methods}

\subsubsection{Analysis}

Fluoride and other anions, chloride, nitrate, phosphate and sulfate were analyzed using Ion chromatography on Dionnex AS14 using $3.5 \mathrm{mM} \mathrm{NaCO}_{3} / 1.0 \mathrm{mM} \mathrm{NaHCO}_{3}$ eluent while cations such as sodium, potassium, calcium and magnesium were analyzed on Dionnex CS16 using $3.0 \mathrm{mM}$ methylsulphonic acid eluent. Aluminium and iron were determined on Jenway $6405 \mathrm{UV}-\mathrm{V}$ spectrophotometer, total hardness $\left(\mathrm{mg} \mathrm{CaCO}_{3} / \mathrm{L}\right)$ was determined titrimetrically, total solids and total non-dissolved solids were determined at $105^{\circ} \mathrm{C}$ as described in APHA. pH, electroconductivity (EC) and turbidity were determined using 827 pHlab Metrohm electrode (Switzerland), EC/TDS pocket meter (Martin instruments, model number EC 55) and DRT-15CE Turbidimeter (USA) respectively.

\subsubsection{Batch Experiments}

Fluoride uptake capacity using raw bauxite was optimized on a defluoridation clay pot diameter $7.0 \mathrm{~cm}$ and 
height $33.0 \mathrm{~cm}$. Raw bauxite dosages between 0.080 to $0.200 \mathrm{~kg} / \mathrm{L}$; retention times between 1.0 to 30 min were investigated. Sand and charcoal at a constant ratio of 1:3 and at combined dosages of between 0.400 to 0.720 $\mathrm{kg} / \mathrm{L}$ were optimized for water clarification at the optimum bauxite dosage and retention time. The dosages of bauxite and sand/charcoal mixture were arrived at from earlier equilibrium studies done within this work. A groundwater sample with fluoride concentration of $6.17 \mathrm{mg} / \mathrm{L}$ was used to evaluate fluoride uptake capacity. The experimental protocol is as detailed in Figure 1: Raw water was fed at the top of the defluoridator and allowed to trickle through the sorbent, sand and charcoal then collected at the tap. In optimization of dosage and contact time sand and charcoal were omitted. The total volume of treated water $(\mathrm{L})$ and the total time taken for the water to elute ( $\mathrm{min})$ were also determined. All the analyses were done in triplicates.

The average elution rate, $\mathrm{V}_{\mathrm{r}}(\mathrm{L} / \mathrm{min})$; was calculated based on:

$$
\mathrm{V}_{\mathrm{r}}=\text { Total eluted volume } / \text { Total elution time }
$$

The specific safe water yield (SSY) defined as the volume of treated water (L) containing less than $1.5 \mathrm{mg} \mathrm{F} / \mathrm{L}$ per $\mathrm{kg}$ adsorbent was calculated based on the equation:

$$
\mathrm{SSY}=\frac{\mathrm{v}}{\mathrm{M}} \times 1 \mathrm{~kg}
$$

where $\mathrm{V}$ is the volume of treated water $(\mathrm{L})$ with less than $1.5 \mathrm{mg} \mathrm{F}^{-} / \mathrm{L}$ for a given sorbent dosage, $\mathrm{M}(\mathrm{kg})$. Fluoride uptake capacity, FUC was also calculated according to:

$$
F U C=\frac{C_{i}-C_{f}}{M} \times V
$$

Where $C_{i}, C_{f}, M$ and $V$ are the initial and final fluoride concentrations $(\mathrm{mg} / \mathrm{L})$ while $\mathrm{M}$ and $\mathrm{V}$ are the sorbent mass $(\mathrm{kg})$ and volume of treated water $(\mathrm{L})$ respectively

\subsubsection{Development of an Empirical Model}

To develop a linear empirical model relating cross sectional area, $\mathrm{A}\left(\mathrm{cm}^{2}\right)$ and height, $\mathrm{h}(\mathrm{cm})$ of defluoridation units to the specific safe water yield of the form:

$$
Y=m\left(\frac{h}{A}\right)+C
$$

Where $\mathrm{Y}$ is the specific safe water yield $(\mathrm{L} / \mathrm{kg}), \mathrm{m}$ is the gradient $(\mathrm{L} \mathrm{cm} / \mathrm{kg})$ and $\mathrm{C}$ is a constant $(\mathrm{L} / \mathrm{kg})$; defluoridation units of different diameters and heights were used for defluoridation at $0.150 \mathrm{~kg} / \mathrm{L}$ dosage and $15.0 \mathrm{~min}$ contact time. The dimensions of the four defluoridation units used are reported in Table 2 . The defluoridation units in the order DDU 1, DDU 2, DDU 3 and DDU 4 were packed with $0.150,0.300,0.450$ and $1.500 \mathrm{~kg}$ bauxite; $0.720,1.440,2.160$ and $7.200 \mathrm{~kg}$ sand/ charcoal mixture respectively as in Figure 1.

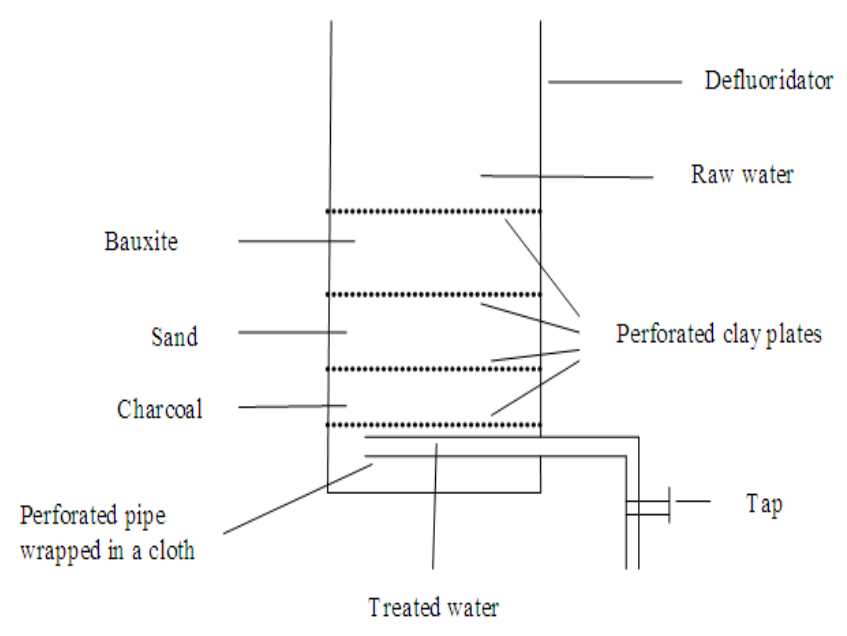

Figure 1. Systematic diagram of DDU 1 in water clarification 
Successive batches of 1.0, 2.0, 3.0 and $10 \mathrm{~L}$ in intermittent mode respectively of high fluoride groundwater was then fed into the defluoridation units. The treated water was collected and analyzed for fluoride until $1.5 \mathrm{mg} / \mathrm{L}$ concentration was exceeded. The specific safe water yield was then computed based on Equation 2.

Table 2. Dimensions of defluoridation units

\begin{tabular}{lllll}
\hline Parameter & DDU 1 & DDU 2 & DDU 3 & DDU 4 \\
\hline Height $(\mathrm{cm})$ & 33.0 & 36.0 & 34.0 & 42 \\
Diameter $(\mathrm{cm})$ & 7.0 & 9.8 & 11.8 & 19.8 \\
Cross sectional area $\left(\mathrm{cm}^{2}\right)$ & 38.5 & 75.4 & 109.4 & 307.9 \\
h/A $\left(\mathrm{cm}^{-1}\right)$ & 0.857 & 0.477 & 0.311 & 0.136 \\
Volume capacity (L) & 1.2 & 2.7 & 3.7 & 12.9 \\
\hline
\end{tabular}

\section{Results and Discussion}

\subsection{Optimization of Dosage}

\subsubsection{Effect of Dosage on Fluoride Removal Efficiency and Uptake Capacity}

Fluoride removal efficiency and uptake capacity for successive defluoridation cycles of treated water at different bauxite dosages using model defluoridator, DDU 1 are shown in Figures 2 and 3 respectively. For all the dosages $(0.080-0.200 \mathrm{~kg} / \mathrm{L})$, fluoride removal efficiency and uptake capacity decreased at each successive defluoridation cycle as more water is treated and more fluoride eluted due to the exhaustion of the active sites for fluoride sorption on the adsorbent. The same reason accounts for the increase in the concentrations of anions (chlorides, sulphates and carbonates) (data not shown) that may compete with fluoride for adsorption on bauxite. $\mathrm{pH}$ of the treated water also increased as more water eluted which may be attributed to ligand exchange between fluoride and hydroxide anions on the bauxite surface according to equations 5 and 6 :

$$
\begin{gathered}
\equiv \mathrm{Al}(\mathrm{OH})_{3}+3 \mathrm{~F}^{-} \leftrightarrow \equiv \mathrm{Al}(\mathrm{F})_{3}+3 \mathrm{OH}^{-} \\
\equiv \mathrm{FeO} . \mathrm{OH}+\mathrm{F}^{-} \leftrightarrow \equiv \mathrm{FeO} . \mathrm{F}+\mathrm{OH}^{-}
\end{gathered}
$$

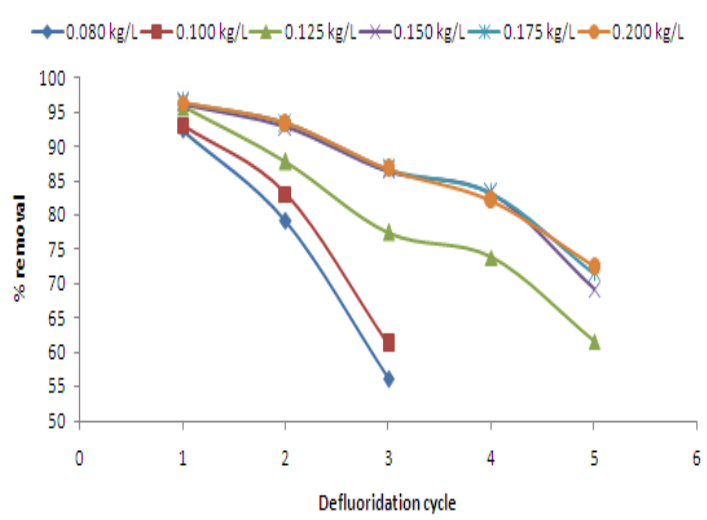

Figure 2. Fluoride removal efficiency (\%) at different bauxite dosages for successive defluoridation cycles in DDU 1, pH 8.13 and initial fluoride $6.17 \mathrm{mg} / \mathrm{L}$

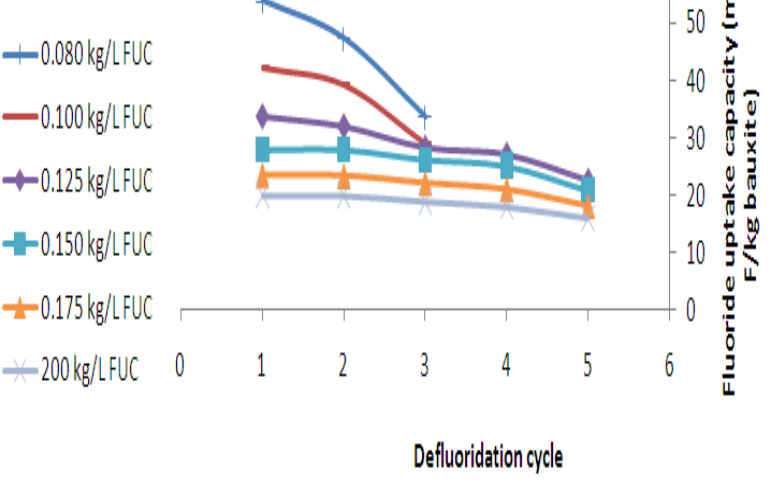

Figure 3 Fluoride uptake capacity (mg F- / kg bauxite) at different bauxite dosages for successive defluoridation cycles in DDU 1, pH 8.13 and initial fluoride $6.17 \mathrm{mg} / \mathrm{L}$

Although the changes in the concentrations of the fluoride and hydroxide anions were non - stoichiometric the surface complexation mechanisms are justified on the basis of the percent compositions of $\mathrm{Al}(\mathrm{OH})_{3}$ and $\mathrm{FeO} . \mathrm{OH}$ in bauxite which are $43 \%$ and $14.2 \%$ respectively (Table 3) (GSoM, 2003). 
Table 3. Mineral composition of Mulanje bauxite

\begin{tabular}{ll}
\hline Mineral composition & \% composition \\
\hline $\mathrm{Al}_{2} \mathrm{O}_{3}$ & 43.3 \\
Free quartz & 13.3 \\
Combined silica & 2.2 \\
$\mathrm{FeO} . \mathrm{OH}$ & 14.2 \\
$\mathrm{TiO}_{2}$ & 1.8 \\
$\mathrm{Kaolinite}$ & $<5.0$ \\
$\mathrm{Na}_{2} \mathrm{O}+\mathrm{K}_{2} \mathrm{O}$ & 28.8 \\
\hline
\end{tabular}

Fluoride removal efficiency for each cycle of treated water increases with increasing bauxite dosage (Figure 2). However the increase is not infinite because at dosages above $0.150 \mathrm{~kg} / \mathrm{L}$ fluoride removal efficiency does not significantly increase ( $\mathrm{p}$ greater than 0.05 ). $0.150 \mathrm{~kg} / \mathrm{L}$ was consequently regarded as the optimized dosage for DDU1. Increased removal of fluoride with increase in bauxite dosage is attributed to increase in number of active sites for fluoride adsorption however at high bauxite dosage there is limited amount of fluoride that may adsorb so percent removal becomes constant. This behaviour for fluoride adsorption is consistent with the findings of other researchers (Mjengera and Mkongo, 2003; Srimurali et al., 1998).

The fluoride uptake capacity for each cycle of treated water decreases with increasing bauxite dosage (Figure 3). The phenomenon is called the solid effect. The major reasons that are advanced include occupied volume of suspended solids and aggregation of particles that prevent optimization of adsorption of sorbents (Celorie et al., 1989; Voice et al., 1983). Fluoride uptake capacity is however lower than that reported in literature for bauxitic materials, greater than $500 \mathrm{mg} / \mathrm{kg}$ (Chauhan et al., 2007); which may be attributed to different operating conditions such as defluoridator design, $\mathrm{pH}$, competing ions and that raw bauxite containing a lot of impurities was used which may not be a good fluoride sorbent. High water $\mathrm{pH}$ must be the main attribute of the low defluoridation capacity for the present system because $\mathrm{OH}^{-}$competes with $\mathrm{F}^{-}$for sorption on the bauxite surface. Low water $\mathrm{pH}$ would also be unfavorable for fluoride sorption as $\mathrm{F}^{-}$forms the slightly soluble HF. In fact an optimum $\mathrm{pH}$ for fluoride sorption using the Mulanje bauxite was about 5.5 (Sajidu et al., 2008).

\subsubsection{Effect of Dosage on Specific Safe Water Yield}

Figure 4 is a plot of the specific safe water yield (SSY, L/kg) as a function of bauxite dosage. The specific safe water yield ranged from a minimum of $16.5 \mathrm{~L} / \mathrm{kg}$ to a maximum of $22.5 \mathrm{~L} / \mathrm{kg}$ for dosages of 0.200 and 0.150 $\mathrm{kg} / \mathrm{L}$ respectively. Though it would be expected that SSY should remain the same with increase in sorbent dosage at dosages greater than $0.150 \mathrm{~kg} / \mathrm{L}$ as fluoride removal efficiency does not change significantly, it increased to a maximum at the optimum dosage $(0.150 \mathrm{~kg} / \mathrm{L})$ and declined thereafter. A higher amount of adsorbent (greater than $0.150 \mathrm{~kg} / \mathrm{L}$ ) would increase the amount of sludge without causing an increase in SSY, vindicating the fact that $0.150 \mathrm{~kg} / \mathrm{L}$ was the optimum dosage. The SSY trend may be explained on the basis of SSY being a function of sorbent dosage (M) and eluted water containing less than $1.5 \mathrm{mg} \mathrm{F}^{-/} \mathrm{L}(\mathrm{V})$ (Equation 2). Above the dosage of $0.150 \mathrm{~kg} / \mathrm{L}$ there is no significant increase in $\mathrm{V}$ (p greater than 0.05) although $\mathrm{M}$ was increased (Figure 4). Thus SSY must decrease due to the constancy of $\mathrm{V}$ and its inverse relationship with $\mathrm{M}$. Not only does V not significantly change at dosages greater than $0.150 \mathrm{~kg} / \mathrm{L}$ but the eluted volume is decreased for corresponding cycles for different dosages perhaps explaining why SSY is much lower for the highest dosage investigated. It is also noted that SSY for the raw Malawi bauxite is much lower than that for other materials such as activated alumina (up to $206 \mathrm{~L} / \mathrm{kg}$ adsorbent) (Chauhan et al., 2007) because the bauxite was of low purity and unactivated.

\subsubsection{Effect of Dosage on Elution Rate}

Increasing bauxite dosage also alters the elution rate through alteration of the volume of eluted water as well as the elution time. The elution rate affects fluoride removal efficiency by influencing the residence time of the untreated water in the defluoridator consequently the interaction between the sorbent and the sorbate. A decrease in elution rate should lead to an increase in residence time hence an increase in fluoride removal. It was observed that the elution rate decreases from 0.663 to $0.495 \mathrm{~L} / \mathrm{hr}$ as dosage increases from 0.080 to $0.200 \mathrm{~kg} / \mathrm{L}$ due to an increase in elution time accompanied by a decrease in the eluted volume. The decrease in elution rate is not however consistently accompanied by a corresponding increase in removal efficiency or SSY. At dosages greater 
than $0.150 \mathrm{~kg} / \mathrm{L}$ the expected trend is broken, elution rate continues to decrease, removal efficiency becomes constant and SSY declines. Elution rate is overtaken by other factors in the defluoridation process. Furthermore the correlation between elution rate and SSY is poor $(r=-0.127)$. This points to the complexity and interplay of factors in the defluoridation process in defluoridation units hence points to the need of testing defluoridators to optimize parameters that affect the defluoridation process.

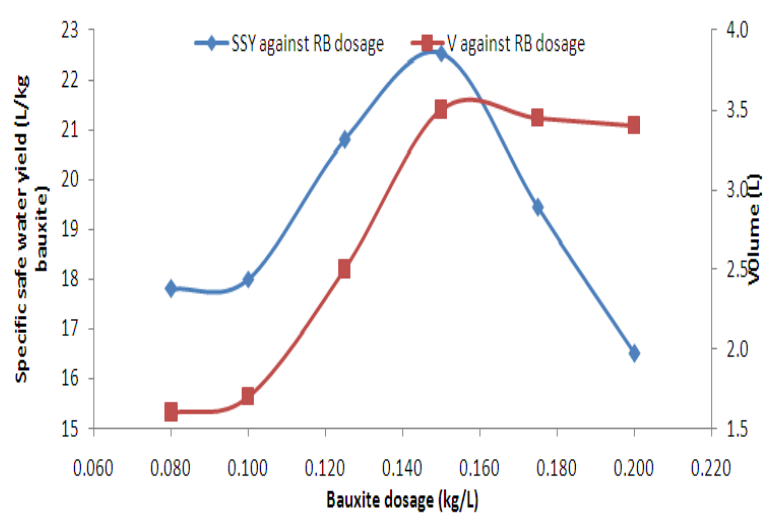

Figure 4. Specific safe water yield and volume of treated water containing $\leq 1.5 \mathrm{mg} \mathrm{F}^{-} / \mathrm{L}$ against bauxite dosage

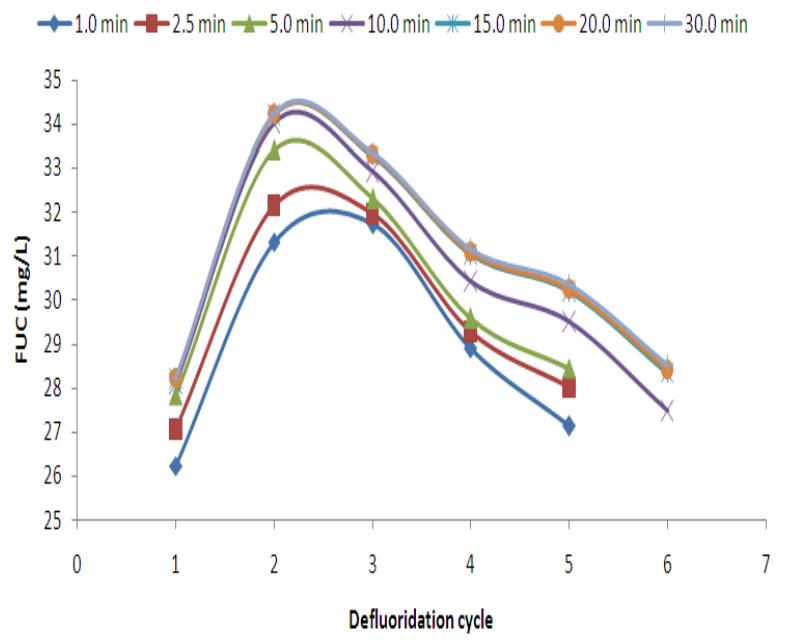

Figure 6. Fluoride uptake capacity (mg F- / kg bauxite) at different contact times for corresponding defluoridation cycles in DDU 1, $\mathrm{pH} 8.17$ and initial fluoride $6.17 \mathrm{mg} / \mathrm{L}$

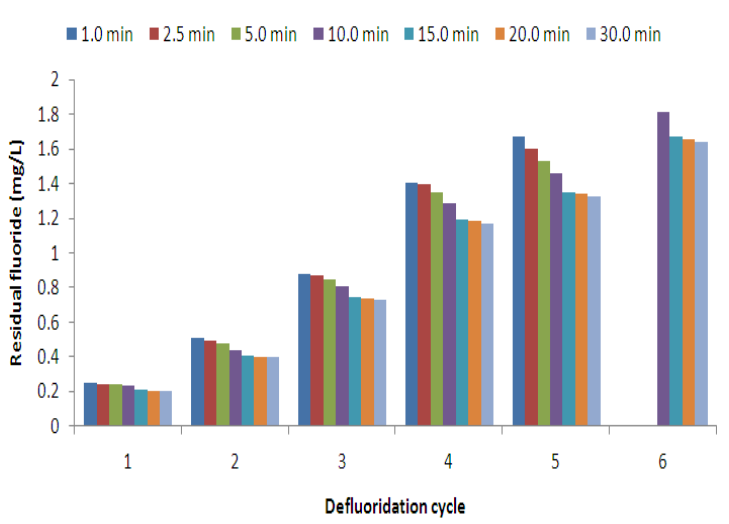

Figure 5. Residual fluoride as a function of defluoridation cycles for corresponding defluoridation cycles at different contact times

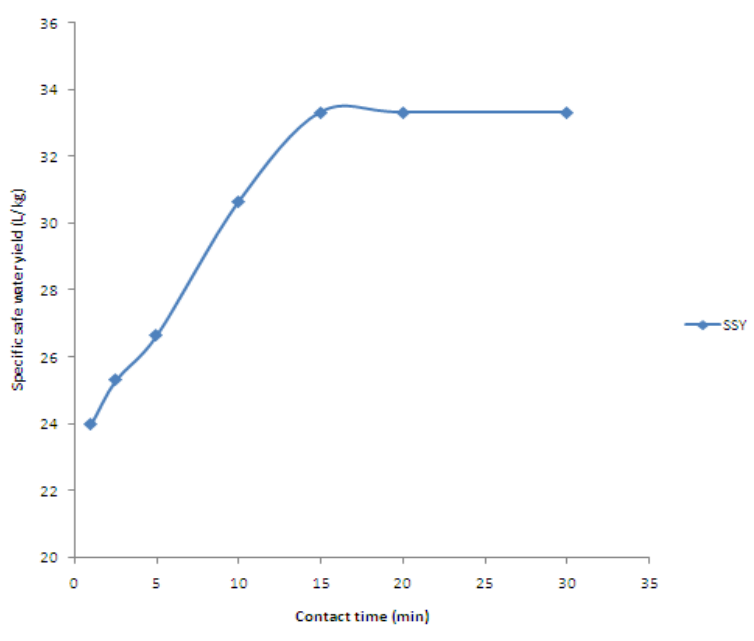

Figure 7. Specific safe water yield against contact time

\subsection{Optimization of Contact Time}

Figures 5 and 6 show the variation of residual fluoride and FUC respectively for corresponding defluoridation cycles of treated water at different contact times. Figure 7 is a plot of SSY against contact time. On the basis of these curves it was established that 15.0 min was the optimum contact time since further increase in contact time neither leads to a decrease in residual fluoride nor an increase in FUC and SSY. Similar contact time (20 min) for batch defluoridators based on bone char are reported in the literature (Korir et al., 2009). As seen from Figure 6, FUC for the first two cycles of treated water at different contact times is not significantly different ( $\mathrm{p}$ greater than 0.05). However as more water is treated the FUC increases with contact time up to $15.0 \mathrm{~min}$ and for 15.0 , 20.0 and $30.0 \mathrm{~min}$ for cycles $3,4,5$ and 6 it is not significantly different (p greater than 0.05 ). Two mechanisms of fluoride removal by bauxite, surface complexation and penetrative diffusion were proposed to account for this behaviour with respect to contact time. During the early stage a high number of surface active sites are available for sorption; surface complexation is the rate determining step. After a lapse of time the remaining surface active 
sites are difficult to occupy due to repulsive forces between the solute on the solid and solute phases, penetrative diffusion becomes rate determining (Hameed et al., 2008). Low contact times do not allow penetrative diffusion which occurs at high contact times, hence FUC for high contact times is increased since more fluoride is sorbed.

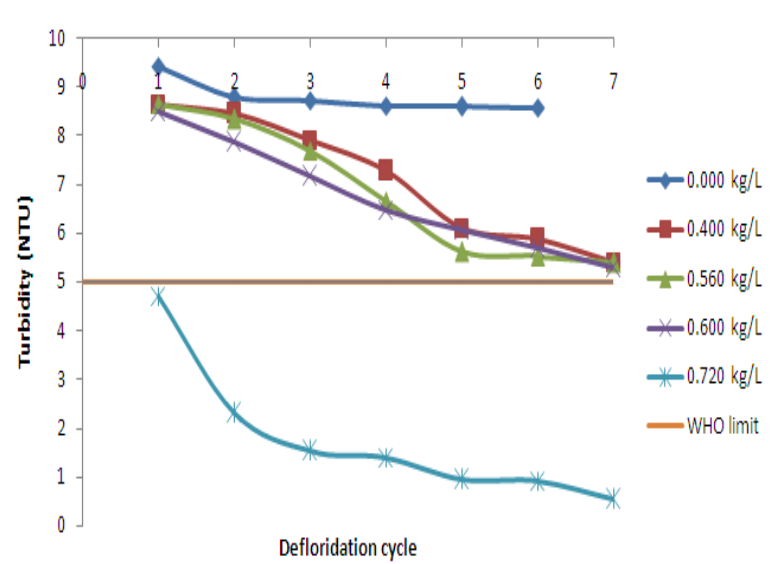

Figure 8 . Turbidity against defluoridation cycle at different dosages of sand and charcoal in turbidity reduction

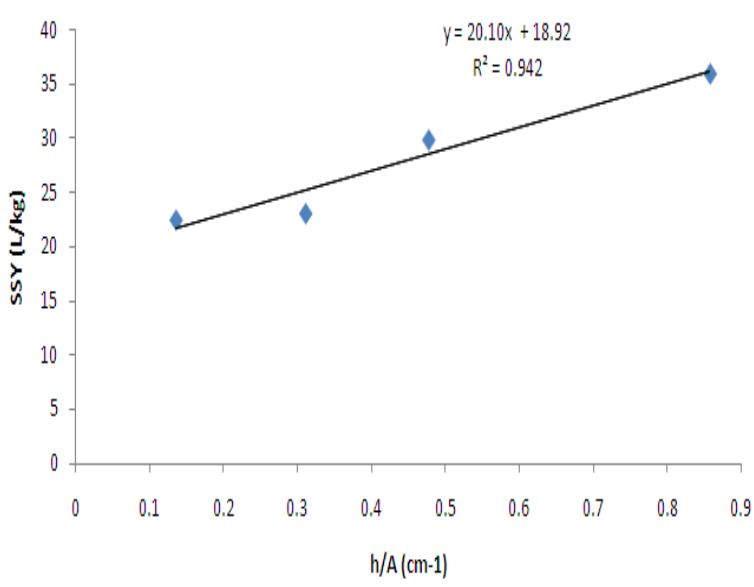

Figure 9. SSY against h/A for different domestic defluoridation units, bauxite dosage $0.150 \mathrm{~kg} / \mathrm{L}$, sand and charcoal dosage $0.720 \mathrm{~kg} / \mathrm{L}$ and contact time $15.0 \mathrm{~min}$

For all the contact times it is noted that FUC increases between cycles 1 and 2 then decreases. To account for this trend Equation 3 is invoked. Since bauxite dosage is constant, FUC depends on residual fluoride and treated water volume. The effect of a small treated water volume tending to decrease FUC outweighs the effect of a small residual fluoride that has a tendency to increase FUC hence FUC is lower for cycle 1 than cycle 2.

To assess the suitability of the defluoridation process in production of drinking water, other water quality parameters in addition to fluoride were also analyzed. All water quality parameters except turbidity did conform to the WHO standards. Furthermore turbidity did increase with the increase in contact time perhaps due to increased interaction between the bauxite and the treated water. Contact time had no significant influence on the elution rate ( $p$ greater than 0.05 ). The non-dependence of elution rate on contact time is attributed to the fact that the treated water has to transverse the same adsorbent depth given a constant adsorbent dosage.

\subsection{Water Clarification}

Figure 8 is a plot of the turbidity of treated water against defluoridation cycle at different combined dosages of charcoal and sand at a constant ratio of 1:3. It is observed that the lower combined dosages of sand and charcoal $(0.400$ to $0.600 \mathrm{~kg} / \mathrm{L}$ ) could not reduce turbidity to less than $5.0 \mathrm{NTU}$, the WHO recommended guideline value regardless of the defluoridation cycle. Thus discarding the first few batches of treated water to get aesthetic drinking treated water at these dosages as proposed by some researchers (Mjengera \& Mkongo, 2003; Korir et al., 2009) in water defluoridation with bone char would not be a feasible option in this instance. However, at a dosage of $0.720 \mathrm{~kg} / \mathrm{L}$ turbidity was reduced from between 9.42 to $4.72 \mathrm{NTU}$ and 8.58 to $0.53 \mathrm{NTU}$ reflecting a turbidity \% removal that increased from $50 \%$ to $94 \%$ as more water is eluted. Consequently $0.720 \mathrm{~kg} / \mathrm{L}$ was deemed as the optimum combined dosage of charcoal and sand for turbidity reduction, with a specific safe water yield of $36.0 \mathrm{~L} / \mathrm{kg}$, at an optimum bauxite dosage of $0.150 \mathrm{~kg} / \mathrm{L}$, contact time $15.0 \mathrm{~min}$ and an elution rate of $0.228 \mathrm{~L} / \mathrm{h}$.

Furthermore other water quality parameters, chloride, nitrate, phosphate, sulfate, sodium, potassium, calcium, magnesium, iron, total hardness, electrical conductivity, $\mathrm{pH}$, total solids and total suspended solids were within the WHO recommended guideline values.

Water turbidity is caused by suspended solids inter alia. However, the reduction of turbidity in treated water by charcoal and sand must be attributed to the trapping of suspended solids because there is high correlation ( $\mathrm{r} \geq$ 0.90 ) between turbidity and suspended solids at different dosages of the water clarifiers (Table 4). 
Table 4. Correlation coefficient between turbidity and suspended solids

\begin{tabular}{lllll}
\hline Charcoal and sand dosage $(\mathrm{kg} / \mathrm{L})$ & 0.400 & 0.560 & 0.600 & 0.720 \\
\hline Correlation coefficients (r) & 0.96 & 0.95 & 0.98 & 0.90 \\
\hline
\end{tabular}

As already pointed out lower dosages of charcoal and sand $(0.400-0.600 \mathrm{~kg} / \mathrm{L})$ could not reduce the turbidity of the defluoridated groundwater to the recommended level (less than 5.0 NTU). The high dosage of charcoal and sand required for adequate reduction of turbidity through removal of suspended solids may be attributed to the low adsorption capacity for particles of charcoal and the limited particle sizes that may be trapped by sand (greater than $25 \mu \mathrm{m})$. To enhance the ability of sand as a filter, coagulants such as alum $\left(\mathrm{Al}_{2}\left(\mathrm{SO}_{4}\right)_{3}\right)$ and polycationic electrolytes that agglomerate colloidal particles are used in conventional water treatment but costs would be prohibitive in a rural domestic defluoridation set-up. Alternatively activated carbon which has a high adsorption capacity through chemiprecipitation is used for water clarification.

The introduction of charcoal and sand, to reduce turbidity and remove color from treated water also enhances the fluoride removal efficiency which may be attributed to a decreased flow rate that allows more interaction between the fluoride and the adsorbent as well as adsorption by charcoal since carbonaceous materials are reported to be fluoride scavengers (Abe et al., 2004). To establish the actual cause of increase in fluoride removal efficiency (elution rate or adsorption by charcoal), untreated water was retained in DDU 1 in absence of bauxite and eluted at the same rate as for the $0.720 \mathrm{~kg} / \mathrm{L}(0.228 \mathrm{~L} / \mathrm{h})$. It was found out that there was no significant decrease in fluoride concentration ( $p$ greater than 0.05 ), thus charcoal did not enhance fluoride removal. This is in agreement with the findings of other researchers (Abe et al., 2004) who also found that charcoal had poor fluoride sorption capacity.

\subsection{Development of an Empirical Model for Dependence of SSY on Defluoridator Size}

So far it has been demonstrated that FUC and SSY depend on the adsorbent dosage, contact time and dosage of water clarifiers. In addition groundwater characteristics, nature of adsorbent and the dimensions of the defluoridation may influence FUC and SSY. To investigate the influence of defluoridator design on SSY, Figure 9 plots SSY as a function of $\mathrm{h} / \mathrm{A}$ where $\mathrm{h}$ is the height of a defluoridator $(\mathrm{cm})$ and $\mathrm{A}$ is its cross sectional area $\left(\mathrm{cm}^{2}\right)$.

It is observed that SSY decreases with increase in the cross sectional area which may be attributed to a decrease in adsorbent depth which entails that the raw water interacts with less adsorbent before elution hence less fluoride is retained in the solid phase. Since the $\mathrm{R}^{2}$ value is not adequate in verifying the suitability of the model in predicting the relationship between SSY and $\mathrm{h} / \mathrm{A}$, the statistical $\chi^{2}$ test was invoked. A $\chi^{2}$ value of 0.96 indicates that the predicted model is in agreement with the experimental data. This finding entails that a defluoridation unit with greater height but less cross sectional area is preferable for fluoride removal.

\section{Conclusion}

Optimum dosage and contact time for domestic defluoridation unit 1 were found to be $0.150 \mathrm{~kg} / \mathrm{L}$ and $15.0 \mathrm{~min}$ respectively. Fluoride uptake capacity was found to decrease with increase in dosage which is consistent with the literature. This was attributed to the 'solid effect'. Increasing bauxite dosage increased removal efficiency through provision of more active site and decrease in elution. Elution rate was however found not to vary with contact time. Fluoride uptake capacity increased as contact time was increased. Optimum combined dosage of sand and charcoal for water clarification at a constant dosage of $3: 1$ was found to be $0.720 \mathrm{~kg} / \mathrm{L}$ for domestic defluoridation unit 1 . With all the desired parameters optimized for domestic defluoridation unit 1 the Specific safe water yield was found to be $36.0 \mathrm{~L} / \mathrm{kg}$ i.e. $36 \mathrm{~L}$ of water containing less than $1.5 \mathrm{mg} \mathrm{F}^{-/} \mathrm{L}$ per kg of bauxite. An empirical model of the form $Y=m x+C$ where $\mathrm{y}$ is the specific safe water yield, $\mathrm{x}$ is the height/cross sectional area ratio of a defluoridator is developed to show the significance of defluoridator design in defluoridation. This study has shown that local bauxite from Mulanje is effective in scavenging for fluoride from groundwater therefore the usability of the technology developed must further be explored to see whether the community at risk from fluorosis would accept the technology.

\section{Acknowledgements}

We are grateful to the International Program in Chemical Sciences (IPICS) through project code, MAL: 02 for the financial and material support rendered towards this work. Special thanks also go to Mr Chimbiri of Geological Survey and Mr Kapindu of Chancellor College whose assistance in collection of bauxite and groundwater was invaluable. 


\section{References}

Abe, I., Iwasaki, S., Tokimoto, T., Kawasaki, N., Nakamura, T., \& Tanada, S. (2004). Adsorption of fluoride ions onto carbonaceous materials. Journal of Colloid and Interface Science, 275, 35-39. http://dx.doi.org/10.1016/j.jcis.2003.12.031

Carter, G. S., \& Bennet, T. D. (1973). The Geology and Mineral Resources of Malawi (2nd Ed.). Zomba: Government Print, Chapter 6.

Celorie, J. A., Woods, S. L., Vingston, T. S., \& Istok, J. D. (1989). A comparison of sorption equilibrium distribution coefficients using batch and centrifugation methods. Journal of Environmental Quality, 18, 307-313. http://dx.doi.org/10.2134/jeq1989.00472425001800030012x

Chauhan, V. S., Dwivedi, P. K., \& Yenga, L. (2007). Investigations on activated alumina domestic based defluoridation units. Journal of Hazardous Materials, 139(1), 103-107. http://dx.doi.org/10.1016/j.jhazmat.2006.06.014

GSoM. Mulanje Mountain Bauxite Project Profile. (2003). Zomba. Geological Survey of Malawi.

Hameed, B. H., Tan, I. A. W., \& Ahmad, H. L. (2008). Adsorption isotherm, kinetic modelling and mechanism of 2, 4, 6-trichlorophenol on coconut hask based activated carbon. Chemical Engineering Journal, 144, 235-244. http://dx.doi.org/10.1016/j.cej.2008.01.028

Korir, H., Mueller, K., Korir, L., Kubai, J., Wanja, E., Wanjiku, N., ... Johnson, C. A. (2009). The development of bone char-based filters for fluoride removal from drinking water. Proceedings of the 34th WEDC International Conference, Water, Sanitation and Hygiene: Sustainable Development and Multisectoral Approaches, Addis Ababa, Ethiopia, referred paper 189.

Mjengera, H. \& Mkongo, G. (2003). Appropriate defluoridation technology for use in fluoritic areas in Tanzania. Physics and Chemistry of the Earth, 1097-1104. http://dx.doi.org/10.1016/j.pce.2003.08.030

MBS. Drinking water-Specifications MS14 2005.

Sajidu, S. M., Masamba, W. R. L., Thole, B. \& Mwatseteza, J. F. (2008). Groundwater fluoride levels in villages of Southern Malawi and removal studies using bauxite. International Journal of Physical Sciences, 3, 1, 001-011

Srimurali, M., Pragathi, J., \& Karthikeyan, J. (1998). A study on removal of fluoride ferom drinking water by adsorption onto low-cost materials. Environmental Pollution, 99, 285-289. http://dx.doi.org/10.1016/so269-7491('97)00129-2

Voice, T. C., Rice, C. P., \& Weber, W. J. (1983). Effects of solids concentration on sorptive partitioning of hydrophobic pollutants in aquatic systems. Enviromental Science Technology, 17, 513-518. http://dx.doi.org/10.1021/es001159004

WHO. (1994). Fluorides and Oral Health. Technical Report series No 846. Geneva. World Health Organisation

WHO. (2004). Guidelines for drinking water quality. (3rd ed.). Recommendations. Geneva. World Health Organisation

Zeni, M., Riveros, R., Melo, K., Primeri, R., \& Lorenzini, S. (2005). Study on fluoride reduction in artesian wells-water from electrodialysis process. Desalination, 185, 214-244. http://dx.doi.org/10.1016/j.desal.2005.03.080 